\title{
Preparation and Characterization of ZnO-Zeolite Nanocomposite for Photocatalytic Degradation by Ultraviolet Light
}

\author{
Rianyza Gayatri ${ }^{1}$, Tuty Emilia Agustina ${ }^{2 *}$, David Bahrin², \\ Rosdiana Moeksin'2, Gustini Gustini ${ }^{3}$
}

1 Master Program of Chemical Engineering, Environmental Technology, Universitas Sriwijaya, Jl. Srijaya Negara, Bukit Besar, Palembang 30139, South Sumatera, Indonesia

2 Chemical Engineering Department, Faculty of Engineering, Universitas Sriwijaya, Jl. Raya Palembang Prabumulih Km. 32 Indralaya, Ogan Ilir 30662, South Sumatera, Indonesia

3 Mechanical Engineering Department, Faculty of Engineering, Universitas Sriwijaya, Jl. Raya Palembang Prabumulih Km. 32 Indralaya, Ogan Ilir 30662, South Sumatera, Indonesia

* Corresponding author's e-mail: tuty_agustina@unsri.ac.id

\begin{abstract}
The increasing growth of the textile industry does not only provide benefits in the economic sector but also has the potential to damage the environment, because it generates the dye wastewater which is hard to eliminate. Procion red is one of the synthetic textile dyes that is toxic to the aquatic environment and it needs to be processed properly. The photocatalytic method of processing dye wastewater is the most effective, because it can remove the harmful pollutants in the dye wastewater. This study aimed to prepare and characterize the ZnO-Zeolite nanocomposites for photocatalytic applications tested with a $50 \mathrm{mg} / \mathrm{L}$ procion red dye sample. The nanocomposites consisted of the $\mathrm{ZnO}$ semiconductors and synthetic zeolite adsorbents prepared by using the sol-gel method. The dye degradation test was carried out under the irradiation conditions with ultraviolet (UV) lamp. Apart from the ZnO-Zeolite nanocomposite, testing was also carried out with the synthetic zeolite and $\mathrm{ZnO}$. The results of SEM-EDX and XRD characterization proved that the nanocomposite forming components were $\mathrm{ZnO}$ and zeolite and could be seen from the resulting peaks. BET showed that the surface area value of the ZnO-Zeolite nanocomposite increased to $95.98 \mathrm{~m}^{2} / \mathrm{g}$, the pore size of the $\mathrm{ZnO}-\mathrm{Zeolite}$ nanocomposite was $4.42 \mathrm{~nm}$, and the total pore volume was $0.08 \mathrm{~cm}^{3} / \mathrm{g}$. The obtained average crystalline size of $\mathrm{ZnO}$-Zeolite nanocomposite was $32.87 \mathrm{~nm}$. The percentage of dye degradation using the $\mathrm{ZnO}-\mathrm{Zeolite}$ nanocomposite for 120 minutes has reached $90.42 \%$.
\end{abstract}

Keywords: nanocomposite, $\mathrm{ZnO}$, synthetic zeolite, sol-gel, photocatalytic, procion red

\section{INTRODUCTION}

The textile industry plays an important role in the Indonesian industry and increases rapidly. The Ministry of Industry in Indonesia shows that the export value of the textile industry and textile products sector throughout 2019 reached US\$ 12.9 billion and the growth performance of the textile industry was recorded to have increased by $19 \%$. However, apart from contributing to the economy, the textile industry also has the potential to damage the environment. The color waste causes pollution that is toxic to the environment. The waste containing dyes usually consist of non-biodegradable organic compounds that can cause pollution in the environment, especially in the aquatic environment, so that the dye must be oxidized into simpler molecules (Viswanathan, 2018).

Procion red is one type of synthetic dye that is most often used in the textile industry, such as the fabric or batik home industry. This dye is very difficult to degrade. Consequently, it is necessary to have an effective treatment to reduce the color content and organic compounds in the textile wastewater. Several methods of processing the 
textile wastewater have been developed by many researchers, namely by the processes of adsorption, chlorination, ozonation, and biodegradation (Amri and Utomo, 2017).

Some of the weaknesses of this methods are in addition to the less than optimal degradation results (Naimah and Rahyani, 2014) - high operational costs, generation of secondary pollutants, and the fact that these methods are still relatively difficult to apply in Indonesia. The use of photocatalysts with the photodegradation method is the most effective alternative in the wastewater treatment. The photodegradation method utilizes photocatalysts and irradiation by UV light (Agustina et al., 2015). Photocatalysis is used to degrade the organic components with the help of ultraviolet light (Sharfan et al., 2018). The UV radiation required for the photocatalytic processes can be obtained from artificial sources or the Sun (Krzeminska et al., 2015).

$\mathrm{TiO}_{2}$ and $\mathrm{ZnO}$ are semiconductors that are most widely used as photocatalysts in the photocatalytic degradation of dye wastewater. However, $\mathrm{ZnO}$ is more readily available, cheaper, and $\mathrm{ZnO}$ can absorb more of the solar spectrum than $\mathrm{TiO}_{2}$, so that $\mathrm{ZnO}$ has a higher photocatalytic activity (Saravanan et al., 2013). $\mathrm{ZnO}$ is widely used as a photocatalyst, because it has good chemical stability, and is classified as a non-toxic material (Kusdianto et al., 2019).

One of the disadvantages of the photocatalytic process is the weak adsorption capacity. In order to overcome this problem, the photocatalyst can be combined with an adsorbent as a supporting material. Wismayanti et al., (2015) combined the $\mathrm{ZnO}$ photocatalyst and activated charcoal adsorbent used for the degradation of the methylene blue dye.

The combination with this adsorbent aims to optimize the photocatalytic contact with dye pollutants. In addition, the adsorbent does not need to be regenerated, because the pollutants that have stuck to the adsorbent will be degraded in situ by the photocatalyst, so that adsorbent saturation can be avoided. Good adsorbents have high adsorption capacity and will certainly result in a high absorption percentage (Darmansyah et al., 2016).

Zeolite is a porous material that has been widely used as a catalyst, adsorbent, and ion exchanger (Rahman et al., 2018). Synthetic zeolite was chosen to be the adsorbent because synthetic zeolite has the physical properties that much better than those of natural zeolite. Besides, synthetic zeolite has a uniform pore size and is more evenly distributed so that the adsorption results will also be maximized.

One of the most successful methods for preparing the nano-sized metal oxide materials is the sol-gel method; hence, this method is suitable for application in the preparation process of the ZnO-Zeolite nanocomposites. The sol-gel method is used for the preparation of thin films and powder-shaped materials, where the alkoxides are hydrolyzed by alcohol to metal hydroxides (Rahman et al., 2018).

In this research, the characterization and preparation process of the $\mathrm{ZnO}-\mathrm{Zeolite}$ nanocomposites for the photocatalysis was carried out by testing the degradation of the procion red dyes using the sol-gel method. The advantage of the $\mathrm{ZnO}-\mathrm{Zeolite}$ composite produced is that the $\mathrm{ZnO}$ Zeolite composite is nano-sized so that its photocatalytic activity is maximized and is indicated by the high dye degradation results. The costs required are also lower due to the use of $\mathrm{ZnO}$ photocatalyst raw materials and zeolite adsorbents which are more affordable than other materials.

\section{MATERIALS AND METHODS}

\section{Materials and preparation}

Precursor $\mathrm{Zn}\left(\mathrm{CH}_{3} \mathrm{COO}\right)_{2} \cdot 2 \mathrm{H}_{2} \mathrm{O}$ (Zinc Acetate), $\mathrm{ZnO}$, synthetic zeolite, $99 \%$ ethanol, $\mathrm{NaOH}$, and $\mathrm{HCl}$ were supplied from Sigma Aldrich and synthetic procion red powder dyes were obtained from dye stuff store (Fajar Setia, Jakarta).

Zeolite is activated to increase its purity (Wulandari et al., 2019). Synthetic zeolites that were crushed with grinders and sifted with 400 mesh sieve were then activated by heating in an oven at $110^{\circ} \mathrm{C}$ for 2 hours, then washed with $0.4 \mathrm{M} \mathrm{HCl}$ for 1 hour, followed by washing with distilled water until neutral. The synthetic zeolite was filtered and dried in an oven at $110^{\circ} \mathrm{C}$ for 120 minutes.

\section{Materials characterization}

Zeolite before activation, zeolite after activation, and $\mathrm{ZnO}$-Zeolite Nanocomposite were characterized by X-Ray diffraction (XRD), Scanning Electron Microscope-Energy Dispersive X-ray (SEM-EDX), and Brunauer-Emmett-Teller (BET). XRD analysis was carried out to see the crystal structure based on the information on the 
peaks of the scattering angle (XRD Bruker D8 Advance), SEM-EDX analysis to see the morphology or surface image of the material (SEMEDX Hitachi SU3500), and BET for specific surface area, mean pore size, and the pore volume in the sample (BET Nova 4200e).

\section{Preparation of the ZnO-Zeolite nanocomposite}

$\mathrm{Zn}\left(\mathrm{CH}_{3} \mathrm{COO}\right)_{2} \cdot 2 \mathrm{H}_{2} \mathrm{O}$ precursor is added with synthetic zeolite that has been activated in the precursor and synthetic zeolite ratio of 2:1 (Salam et al., 2018), then dissolved in $80 \mathrm{~mL}$ of $99 \%$ ethanol. The precursor and zeolite mixture was heated to $76^{\circ} \mathrm{C}$ for 120 minutes while stirring in a reflux flask. Then, $225 \mathrm{~mL}$ of $2 \mathrm{M} \mathrm{NaOH}$ was added to the solution and stirred for 1 hour. The mixture was allowed to stand for 12 hours and was then filtered with a Whattman filter paper. The precipitate obtained was then heated in an oven at $60^{\circ} \mathrm{C}$ for 24 hours and then stored in a desiccator to keep it dry. The ZnO-Zeolite nanocomposites were analyzed by BET, SEM-EDX, and XRD.

\section{Photocatalytic Degradation Test}

The ZnO-Zeolite nanocomposite was tested in a degradation process of $50 \mathrm{mg} / \mathrm{L}$ procion red synthetic dye. The photocatalytic test was carried out by using a UV lamp. The dye photodegradation was also applied with synthetic zeolite and Zinc Oxide $(\mathrm{ZnO})$ as a comparison.

The nanocomposite of $\mathrm{ZnO}$-synthetic zeolite was weighed in the amount of $0.1 \mathrm{~g}$ and then mixed with $25 \mathrm{ml}$ of synthetic dye (Salam et al., 2018) with the concentration of $50 \mathrm{mg} / \mathrm{L}$, the mixture was then stirred in a shaker at $320 \mathrm{rpm}$ and placed in a reactor that has been assembled with ultraviolet lamp (Evaco $254 \mathrm{~nm}$ ). The degradation time started when the UV lamp was turned on and the samples were taken for 5, 10, 15, 20, $25,30,60,90$, and 120 minutes to analyze the color degradation. The samples were taken after the specified time and then filtered by a Whattman filter before the dye concentration was analyzed using a UV-Vis Spectrophotometer.

\section{Analysis of degradation results with a UV-Vis spectrophotometer}

The degraded sample mixture was filtered to separate the ZnO-Zeolite nanocomposite from the procion red synthetic dye. The absorbance and final concentration result of the procion red's dye which has been absorbed by the $\mathrm{ZnO}$ Zeolite nanocomposite was measured using a UV-Vis spectrophotometer at the maximum wavelength. From these absorbance values, the concentration of procion red, as well as the percentage of procion red photodegradation were calculated.

$$
\text { Degradation Percentage }=\frac{(\mathrm{C} 1-\mathrm{C} 2)}{\mathrm{C} 1} \times 100 \%
$$

Eq. (1) shows the formula to calculate the degradation percentage of the dye, where $\mathrm{C}_{1}$ is the initial concentration of dye and $\mathrm{C}_{2}$ is the final concentration of dye that were measured by using a UV-Vis Spechtrophotometer.

\section{RESULTS AND DISCUSSION}

\section{The characterization results of the ZnO-Zeolite nanocomposite}

The characterization of the $\mathrm{ZnO}$-Zeolite nanocomposite was carried out by SEM-EDX, BET, and XRD. The XRD results of zeolite before activation and after activation are presented in Figure 1 (a) and (b).

The diffraction patterns of synthetic zeolites before and after activation show almost the same peaks, but the intensity at the peaks is different. Synthetic zeolite after activation has a decreased peak number. The XRD results of synthetic zeolite before activation showed that peaks were at $2 \theta=$ $10.01^{\circ}, 11.5^{\circ}, 14.01^{\circ}, 22.0^{\circ}, 24.99^{\circ}, 25.5^{\circ}, 26.01^{\circ}$, $29.99^{\circ}$, and $31.9^{\circ}$. After the activation process, the synthetic zeolite diffraction pattern showed that the peak was at $2 \theta$, namely $10.01^{\circ}, 12^{\circ}, 14.99^{\circ}$, $20.11^{\circ}, 22.08^{\circ}, 26.01^{\circ}, 27.11^{\circ}, 29.98^{\circ}$, and $31.00^{\circ}$. This peak indicates the presence of zeolites.

The XRD pattern obtained from Figure 1b) shows that the synthetic zeolite is identified as being compatible with Zeolite A (Na). A good crystal structure with peaks at $2 \theta$ : 7-8, 10-11, 22-24 and 29-31 is characteristic of zeolite A with cubic crystals.

This is similar to the research by Nyankson, (2018), who stated that this type A zeolite records peaks at $2 \theta$ : 7.1, 10.1, 12.4, 16.1, 21.6, 24, 26.1, 27.1, 29.9, and $34.1^{\circ}$. The name and chemical formula of Zeolite A ( $\mathrm{Na}$ ) is Sodium Aluminum Silicate Hydrate $\mathrm{Na}_{96} \mathrm{Al}_{96} \mathrm{Si}_{96} \mathrm{O}_{384} \cdot 216 \mathrm{H}_{2} \mathrm{O}$ ).

Figure 2 shows the results of the XRD characterization related to $\mathrm{ZnO}$. The diffraction pattern 
a)

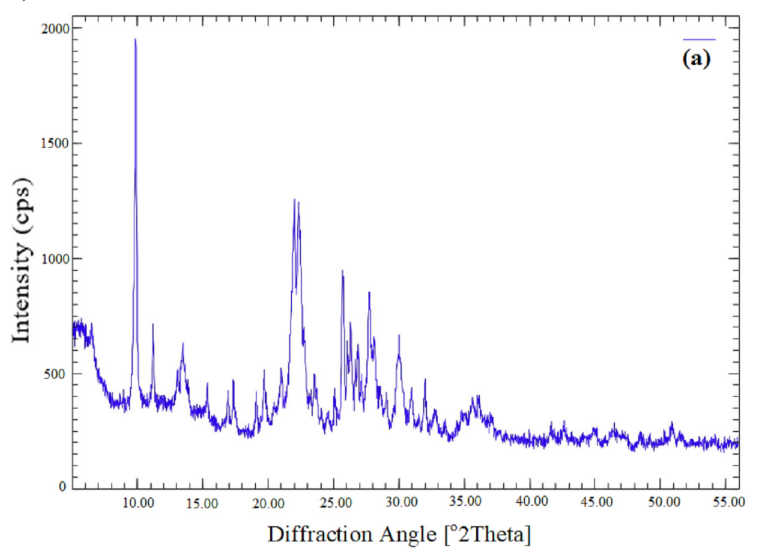

b)

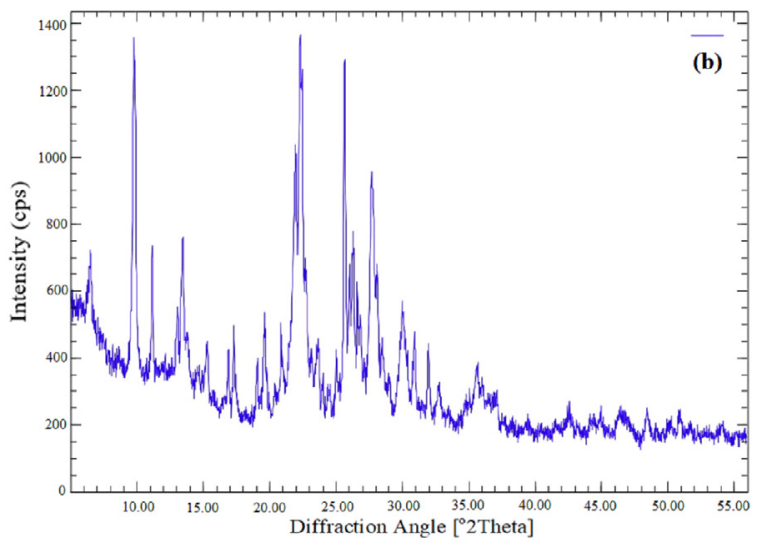

Figure 1. XRD of synthetic zeolite (a) before activation; (b) after activation process

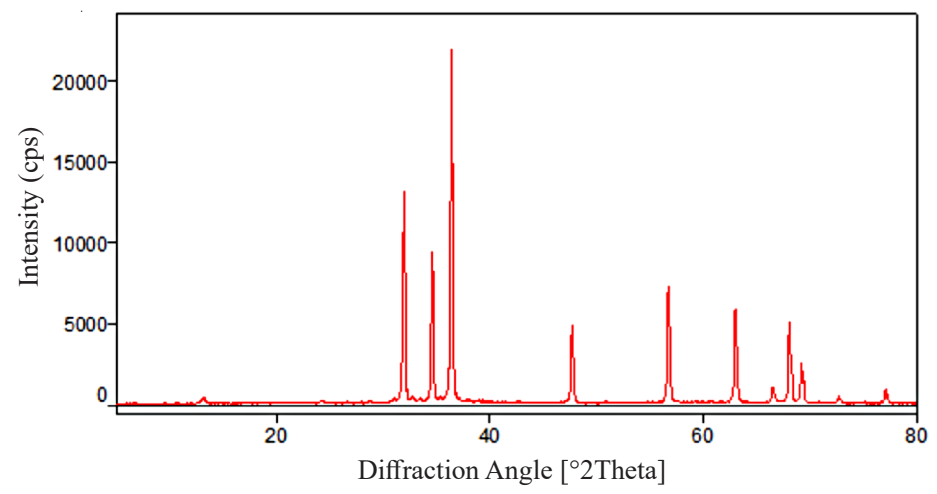

Figure 2. $\mathrm{XRD}$ of $\mathrm{ZnO}$

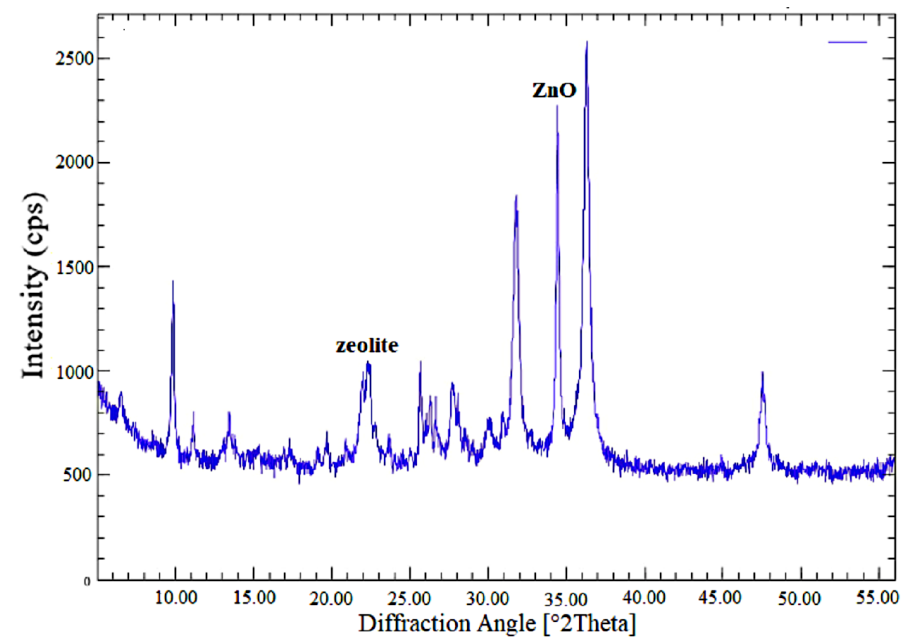

Figure 3. XRD of the $\mathrm{ZnO}-\mathrm{Zeolite}$ nanocomposite

at $\mathrm{ZnO}$ at $2 \theta$ (degree) showed the peak values of $31.95 ; 32.71 ; 34.61 ; 36.44 ; 47.71 ; 56.75 ; 63.02$; $66.54 ; 68.10 ; 69.25 ; 72.71 ; 76.61$ and 77.13 . The XRD ZnO pattern results are identical to the hexagonal phase with the Wurtzite structure with a space group P63mc where, $\mathrm{a}=3.247 \AA$ and $\mathrm{c}=5.198 \AA$ (Alfarisa et al, 2018).
Figure 3 presents the XRD results for the $\mathrm{ZnO}$-Zeolite Nanocomposite. The XRD results obtained were identical to the $\mathrm{ZnO}$ peak with diffraction peaks at $2 \theta$ of $31.43^{\circ}, 34.51^{\circ}, 36.37^{\circ}$, and $54.99^{\circ}$. This is in accordance with the XRD results for hexagonal $\mathrm{ZnO}$ (Mohan and Renjanadevi, 2016) and shows $\mathrm{ZnO}$ with a wurtzite 
structure (Kang et al, 2010). The XRD of nanocomposite showed that other peaks were also found to be around angles of $2 \theta=10.01^{\circ}, 22.12^{\circ}$, $26.11^{\circ}$, and $29.98^{\circ}$, this indicates the presence of synthetic zeolites similar to the results of the study (Nyankson, 2018).

The constituent components of the $\mathrm{ZnO}-\mathrm{Ze}-$ olite nanocomposite can be seen from the peaks produced from the graph, where the degrees of the peaks are shown, which indicate that the constituent components of the nanocomposites are $\mathrm{ZnO}$ and zeolite. The morphology of synthetic zeolites before and after the physical and chemical activation processes showed different results.

On the basis of the XRD data, the calculation performed in accordance to the Scherrer method using X-Powder Software obtained an average crystalline size of the $\mathrm{ZnO}$-Zeolite nanocomposite of $32.87 \mathrm{~nm}$. This suggests that the resulting $\mathrm{ZnO}-Z$ eolite composite has reached the nanosize, so it can be concluded that the $\mathrm{ZnO}$-Zeolite nanocomposites prepared by using the sol-gel method were successfully formed.

The results of zeolite characterization before and after activation with magnifications of 25 thousand times are presented in Figure 4. (a) and (b). The structure and shape of the activated zeolite look more regular and smoother when compared to the zeolite structure before the activation process. The zeolite size that has been activated is also more uniform than that of the zeolite before activation, although it is clear that there are large and small ones.

Figure 5 (a) shows the morphological results of $\mathrm{ZnO}$ with SEM magnification of 50 thousand times. The morphology of $\mathrm{ZnO}$ showed a fairly uniform shape; each particle is evenly distributed and homogeneous. This zinc oxide has a hexagonal phase with the wurtzite structure when viewed from the XRD analysis.

Figure 5 (b) presents the results of SEM characterization of the ZnO-Zeolite nanocomposites with magnification of 25 thousand times. The a)

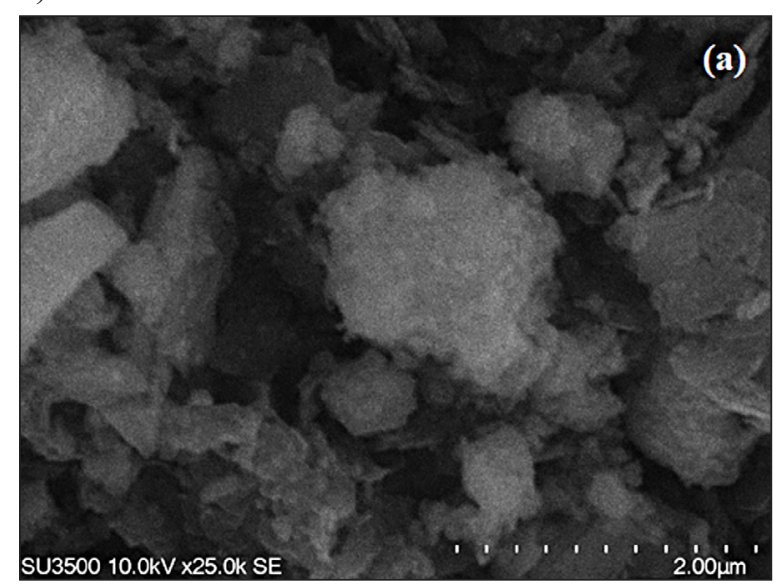

b)

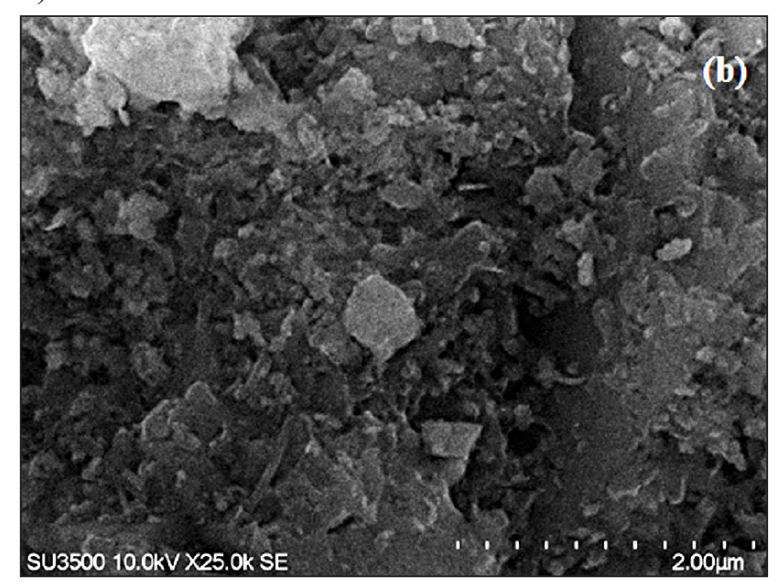

Figure 4. SEM results of synthetic zeolite (a) before activation; (b) after activation process

a)

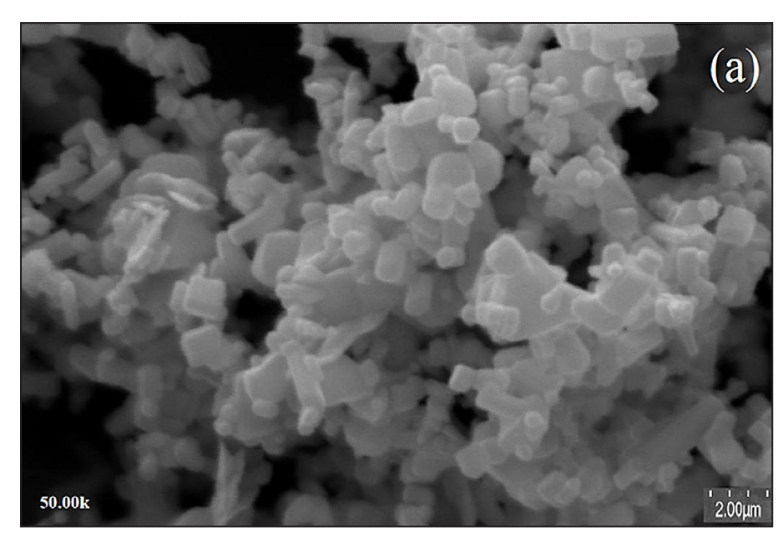

b)

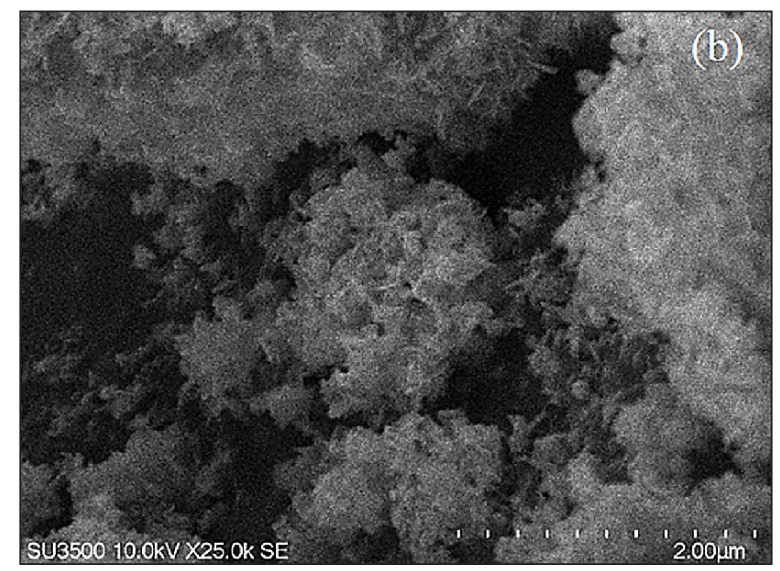

Figure 5. (a) SEM results of $\mathrm{ZnO}$; (b) SEM results of the $\mathrm{ZnO}$-Zeolite nanocomposite 
particle size distribution of the nanocomposites looks more uniform, the distribution of particles is also more even and smoother. The particles also appear to be arranged more uniformly.

From the SEM images of the nanocomposites, it can be seen that there are two types of components in composite with different colors. The results of the SEM morphological analysis were marked by the sticking of $\mathrm{ZnO}$ particles on the surface of the zeolite layer. There is a combination of colors from the two different components, this can be seen from the dark colored zeolite and the light colored $\mathrm{ZnO}$.

Table 1 presents the EDX results of the elements contained in zeolite before and after activation, $\mathrm{ZnO}$, and $\mathrm{ZnO}-\mathrm{Zeolite}$ nanocomposite. From the results of the EDX characterization, it can be seen that the chemical elements in the active zeolite are $43.99 \%$ wt of O element, $30.01 \%$ wt of $\mathrm{Si}, 20.58 \%$ of C, and $5.42 \%$ of $\mathrm{Al}$.

The O, Al, and Si content of synthetic zeolites after the activation process were higher than those of synthetic zeolites before activation. The EDX results of $\mathrm{ZnO}$ show that $\mathrm{ZnO}$ contains zinc and oxygen components with a weight percentage of $65.89 \% \mathrm{Zn}$ and $34.11 \% \mathrm{O}_{2}$. $\mathrm{Zn}$ has a greater percentage than oxygen. The $\mathrm{ZnO}$-zeolite nanocomposite showed a $\mathrm{Zn}$ content with a weight percent of $56.13 \%$ and an oxygen content of $22.42 \%$. The content of $\mathrm{Zn}$ has a greater percentage than other elements. The percentage of $\mathrm{Zn}$ and oxygen present in the $\mathrm{ZnO}$-zeolite nanocomposite indicates that zinc and oxygen are present in the nanocomposite. The presence of $\mathrm{Zn}$ in the nanocomposites is due to the synthesis process made by a sol-gel process using a zinc acetate precursor.
There are other elements in the nanocomposite, such as $\mathrm{C}$ in $12.61 \%, \mathrm{Al}$ in $2.75 \%$ and $\mathrm{Si}$ in $6.09 \%$. The silica and aluminum contents indicate the presence of zeolite in the nanocomposites. These elements indicated that zeolite and $\mathrm{ZnO}$ are contained in nanocomposite and it proved that the ZnO-Zeolite nanocomposite has been successfully synthesized.

The results of BET characterization showed the values of the surface area, pore size, and pore volume of the $\mathrm{ZnO}$-Zeolite nanocomposite sample. Zeolite before and after activation was also analyzed by BET.

The BET results of the three materials are presented in Table 2. The synthetic zeolite before activation has a lower surface area than the zeolite after activation. On the basis of the BET analysis, it is seen that the specific surface area of the synthetic zeolites before activation is $20.30 \mathrm{~m}^{2} / \mathrm{g}$, while the surface area of the zeolites after activation is $47.19 \mathrm{~m}^{2} / \mathrm{g}$. The surface area of the synthetic zeolite after the activation process showed a sufficient increase.

This increase in surface area is due to the opening of the synthetic zeolite pores which were originally covered by impurities. The release of these impurities can open the pores of the synthetic zeolite during heating in the zeolite activation process. The heating process will evaporate the water molecules and other impurities contained in the zeolite crystals so that a cavity with a surface that is larger than before activation is formed. Pore size and pore volume are inversely related to surface area.

The pore size of zeolite before activation was $21.98 \mathrm{~nm}$, decreased to $9.22 \mathrm{~nm}$ after the

Table 1. Results of EDX analysis

\begin{tabular}{|c|c|c|c|c|}
\hline \multirow{2}{*}{ Component } & ZnO & $\begin{array}{c}\text { Synthetic zeolite before } \\
\text { activation }\end{array}$ & $\begin{array}{c}\text { Synthetic zeolite after } \\
\text { activation }\end{array}$ & $\begin{array}{c}\text { ZnO-zeolite } \\
\text { nanocomposite }\end{array}$ \\
\cline { 2 - 5 } & - & 35.24 & 20.58 & 12.61 \\
\hline $\mathrm{C}$ & 34.11 & 43.96 & 43.99 & 22.42 \\
\hline $\mathrm{On}$ & 65.89 & - & - & 56.13 \\
\hline $\mathrm{Al}$ & - & 2.81 & 5.42 & 2.75 \\
\hline $\mathrm{Si}$ & - & 18.00 & 30.01 & 6.09 \\
\hline
\end{tabular}

Table 2. BET characterization results

\begin{tabular}{|l|c|c|c|c|}
\hline \multicolumn{1}{|c|}{ Measurement subject } & ZnO & $\begin{array}{c}\text { Synthetic zeolite } \\
\text { before activation }\end{array}$ & $\begin{array}{c}\text { Synthetic zeolite } \\
\text { after activation }\end{array}$ & $\begin{array}{c}\text { ZnO-zeolite } \\
\text { nanocomposite }\end{array}$ \\
\hline Specific surface area $\left(\mathrm{m}^{2} / \mathrm{g}\right)$ & 19.19 & 20.30 & 47.19 & 95.98 \\
\hline Pore size $(\mathrm{nm})$ & 4.27 & 21.98 & 9.22 & 4.42 \\
\hline Total volume in pores $\left(\mathrm{cm}^{3} / \mathrm{g}\right)$ & 0.04 & 0.11 & 0.09 & 0.08 \\
\hline
\end{tabular}


activation process. The total pore volume of synthetic zeolite decreased from $0.11 \mathrm{~cm}^{3} / \mathrm{g}$ to $0.09 \mathrm{~cm}^{3} / \mathrm{g}$ after activation. The process of heating during zeolite activation causes the release of the impurities that cover the pores of the zeolite and result in reduced pore size and volume. The pore volume shows the pore depth of the zeolite produced.

Meanwhile, the BET $\mathrm{ZnO}$ results show that $\mathrm{ZnO}$ has a surface area of $19.19 \mathrm{~m}^{2} / \mathrm{g}$, a total pore volume of $0.04 \mathrm{~cm}^{3} / \mathrm{g}$ and a pore size of $4.27 \mathrm{~nm}$. ZnO has a smaller surface area. BET characterization results for the ZnO-Zeolite nanocomposites showed the highest surface area value of $95.98 \mathrm{~m}^{2} / \mathrm{g}$. However, the pore size and total pore volume decreased. The pore size of the $\mathrm{ZnO}-Z$ eolite nanocomposite is $4.42 \mathrm{~nm}$, and the total pore volume is $0.08 \mathrm{~cm}^{3} / \mathrm{g}$. This is also due to the ratio of zinc acetate precursor in nanocomposites that are larger than synthetic zeolite so that $\mathrm{ZnO}$ can cover zeolite pores and cause pore size and reduce the pore volume of the nanocomposite. This will have an impact on the degradation process, because the surface area and the pore volume can increase the dissolution rates and adsorption capacity.

\section{The Degradation Results with a UV-Vis Spectrophotometer}

The degradation process of the procion red dye was carried out using different materials, namely $\mathrm{ZnO}-Z$ eolite nanocomposite, synthetic zeolite, and $\mathrm{ZnO}$. The percentage of dye degradation obtained shows the ability of the material to degrade procion red dyes. The best percentage of degradation results was achieved by using the $\mathrm{ZnO}$-Zeolite nanocomposites than the other materials. The absorbance value of the procion red dye solution with a concentration of $50 \mathrm{mg} / \mathrm{L}$ was measured with a UV-Vis spectrophotometer at a wavelength of $470-570 \mathrm{~nm}$ with a range of $10 \mathrm{~nm}$. The maximum wavelength value obtained is $534 \mathrm{~nm}$. The degradation time testing was carried out for 120 minutes, and the change in the final concentration of procion red was measured every specified time.

The percentage results of the procion red degradation using different materials, namely the $\mathrm{ZnO}-\mathrm{Zeolite}, \mathrm{ZnO}$, and synthetic zeolite nanocomposites are presented in Figure 6. The photocatalytic process using the $\mathrm{ZnO}-Z$ eolite nanocomposites resulted in the highest percentage of degradation compared to using $\mathrm{ZnO}$ and synthetic zeolites.

The percentage of degradation results obtained with a concentration of $50 \mathrm{ppm}$ procion red and using a UV lamp. Figure 6 shows the highest degradation percentage value is at 120 minutes using the $\mathrm{ZnO}$-zeolite nanocomposite, which is $90.42 \%$ compared to those using synthetic zeolite and $\mathrm{ZnO}$ only that reached $50.64 \%$ and $80.64 \%$, respectively. Meanwhile, during the initial 5 minutes the dye degradation process has also occurred, but the percentage of degradation or reduction in the concentration of the dye was still low, below 20 percent.

During the initial 25 minutes, degradation with the ZnO-Zeolite nanocomposite also reached a degradation percentage of $53.08 \%$, and over 30 minutes it achieved more than $70 \%$. This shows that the ability of the ZnO-Zeolite nanocomposites under UV light is more effective when compared to using only synthetic zeolite or $\mathrm{ZnO}$-only degradation media, and the $\mathrm{ZnO}-\mathrm{Zeo}-$ lite nanocomposite has high ability when exposed

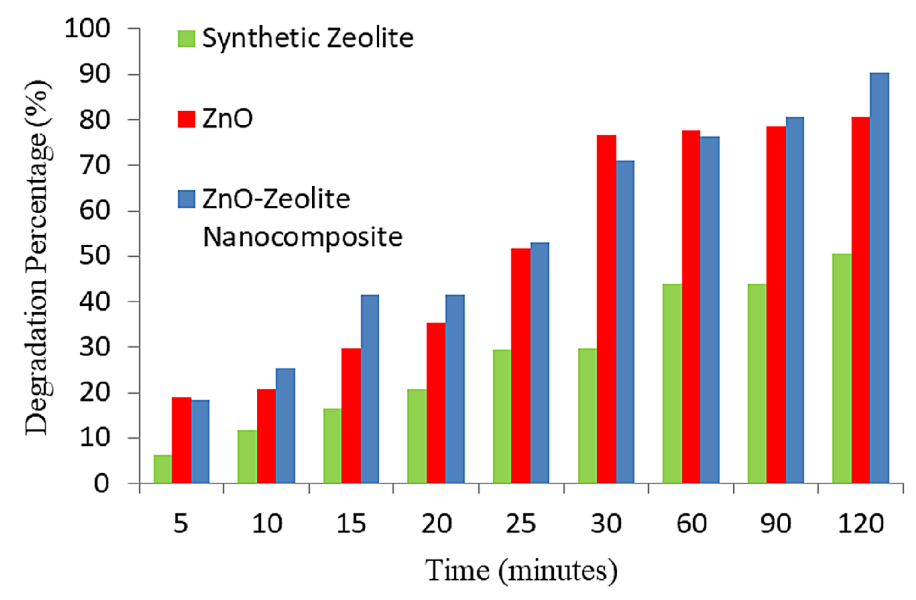

Figure 6. The photodegradation results of procion red $50 \mathrm{mg} / \mathrm{l}$ by using ultraviolet lamp 
to UV light. The smaller the size of the nanocomposites the greater the interaction of the reactants on the particle surface, enabling to achieve maximum degradation.

The correlation between the duration of degradation and the degradation percentage of the procion red is that the percentage of degradation will increase along with the degradation time used. Extending the dye degradation time will increase the formation of hydroxyl radicals as pollutant oxidator, so it gives more impact to the final degradation percentage (Agustina et al., 2015). The ZnO-Zeolite nanocomposite is the most effective material in degrading the procion dyes compared to synthetic zeolite and $\mathrm{ZnO}$.

The degradation test with synthetic zeolite resulted in the lowest percentage of degradation. This is because the dye absorption process is only carried out by the synthetic zeolite adsorbents and only relies on the adsorption process on the zeolite surface. The greater the surface area, the more procion red dye can be absorbed (Indar and Kartikasari, 2017).

The ZnO-Zeolite nanocomposites produce the largest percentage of degradation compared to degradation using only $\mathrm{ZnO}$ or synthetic zeolites. This is because the $\mathrm{ZnO}-\mathrm{Zeolite}$ nanocomposites do not only rely on the absorption of dyes by zeolite adsorbents, but the degradation process of dyes is also assisted by the presence of photocatalysts. $\mathrm{ZnO}$ in nanocomposites will increase the degradability of the dye with the help of a UV lamp. The percentage of dye degradation with an ultraviolet lamp will increase due to the use of a photocatalytic method which will break down the harmful components in the dye and produce safer final waste.

The photocatalytic method produces hydroxyl radicals which will become strong oxidizers in degrading waste, the process is simpler and rapid. Photocatalysis with the combination of the $\mathrm{ZnO}$ photocatalyst and synthetic zeolite adsorbent is more effective and the result of pollutant degradation is maximized. The common chemical feature in the photocatalytic process is the hydroxyl radicals formation as an oxidizer of organic pollutants (Zawadzki et al., 2018). The photodegradation method is cheaper and easy to apply (Agustina et al., 2020). Photocatalysis is a combination of a catalyst and photochemical processes. The photocatalytic process begins with the formation of pairs of positive electron holes $\left(\mathrm{e}^{-}, \mathrm{h}^{+}\right)$in semiconductor particles.
Riyani et al. (2015) explained that semiconductors have an empty valence band and conduction band so that exposure to the Sun or photon energy will cause excitation from the valence band to the conduction band (producing $\mathrm{e}^{-}$) which causes a void or hole in the valence band. Furthermore, the hole will react with $\mathrm{H}_{2} \mathrm{O}$ in the solution to form hydroxyl radicals $(\cdot \mathrm{OH})$ which can degrade organic compounds into $\mathrm{CO}_{2}$ and water. The electrons on the semiconductor surface can react with the electron catcher in the solution, namely $\mathrm{O}_{2}$ to form superoxide radicals $\left(\cdot \mathrm{O}_{2}^{-}\right)$ which can also degrade organic compounds in solution. The radicals of $(\cdot \mathrm{OH})$ and $\left(\cdot \mathrm{O}_{2}^{-}\right)$will continue to form as long as light rays still hit the photocatalyst and will degrade organic compounds into $\mathrm{CO}_{2}$ and $\mathrm{H}_{2} \mathrm{O}$.

\section{CONCLUSION}

The ZnO-Zeolite nanocomposite that has been prepared by using the sol-gel method has surface area value of $95.98 \mathrm{~m}^{2} / \mathrm{g}$, the pore size of $4.42 \mathrm{~nm}$, and the total pore volume of $0.08 \mathrm{~cm}^{3} / \mathrm{g}$. $\mathrm{ZnO}$ and zeolite components were also proven to be contained in nanocomposite, as showed in XRD peaks and SEM-EDX. The obtained average crystalline size of the $\mathrm{ZnO}-Z$ Zeolite nanocomposite amounted to $32.87 \mathrm{~nm}$. The percentage of dye degradation using the $\mathrm{ZnO}-Z$ Zeolite nanocomposite for 30 minutes has reached $70 \%$ and after 120 minutes $-90.42 \%$.

\section{Acknowledgements}

The author would like to thank LPPM Universitas Sriwijaya through Hibah Unggulan Kompetitif 2019. The author also expressed thank to the Laboratory of Environmental Research Center (PPLH) Universitas Sriwijaya and Integrated Research Laboratory Postgraduate Universitas Sriwijaya for laboratory support.

\section{REFERENCES}

1. Agustina T.E., Komala R., and Faizal M. 2015. Application of TiO2 Nano Particles Photocatalyst to Degrade Synthetic Dye Wastewater under Solar Irradiation, Contemp. Eng. Sci. 8(34), 1625-1636.

2. Agustina T.E., Melwita E., Bahrin D., Gayatri R. and Purwaningtyas, I. F. 2020. Synthesis of 
Nano-Photocatalyst ZnO-Natural Zeolite to Degrade Procion Red. International Journal of Technology. 11(3), 472-481.

3. Alfarisa S., Rifai D.A., and Toruan P.L. 2018. X-Ray Diffraction Study on ZnO Nanostructures. Physics Treatis. 2(2), 53-57.

4. Amri S and Utomo M.P. 2017. Peparation and Characterization of $\mathrm{ZnO}-Z$ eolite Composite for Photodegradation of Congo Red. Basic Chemical Journal. 6(2), 29-36.

5. Darmansyah, Simparmin, Ardiana L., and Saputra H. 2016. Mesoporous MCM-41 as Adsorbent: Study of Kinetics and Adsorption Isotherm of Tapioca Wastewater. Journal of Chemical and Environmental Engineering. 11(1), 10-16.

6. Indar K and Kartikasari D. 2017. Bayah Natural Zeolite Adsorption Test and the Effect of Ultraviolet Light on Methylene Blue Waste Degradation. Journal of Engineering. 13(1), 25-32.

7. Kang S., Tan W, Li X., and Jin M. 2010. A Facile Gelatin-Assisted Preparation And Photocatalytic Activity Of Zinc Oxide Nanosheets. Colloids and Surface A: Physicochem. Eng. Aspects. 309, 208-271.

8. Kusdianto K., Widiyastuti W., Shimada M., Nurtono T., Machmudah S., and Winardi S. 2019. Photocatalytic Activity Of Zno-Ag Nanocomposites Prepared By A One-Step Process Using Flame Pyrolysis. International Journal of Technology. 10(3), 571-581.

9. Krzeminska D., Neczaj E., and Borowski G. 2015. Advanced Oxidation Processes For Food Industrial Wastewater Decontamination. Journal of Ecological Engineering. 16(2), 61-71.

10. Mohan A.C. and Renjanadevi B. 2016. Preparation of Zinc Oxide Nanoparticles and its Characterization Using Scanning Electron Microscopy (SEM) and X-Ray Diffraction (XRD). Procedia Technology. 24, 761-766.

11. Naimah S and Rahyani E. 2014. Effect of Nano TiO2 Photocatalyst on Antimicrobial Mechanism of E-Coli and Salmonella. Industrial Research Journal. 5(2), 113-120.
12. Nyankson, Efavi J.K., Yaya A., Manu G., Asare K., Dafuor J., and Abrokwah R.Y. 2018. Synthesis and characterisation of Zeolite-A and Zn-exchanged Zeolite A based on natural aluminosilicates and their potential applications. Cigent Engineering. 5, 1-23.

13. Rahman A., Nurjayadi M., Wartilah R., Kusrini E., Adi P.E., and Degermenci V. 2018. Enhanced activity of $\mathrm{TiO}_{2} /$ Natural zeolite composite for degradation of methyl orange under visible light irradiation. International Journal of Technology. 6, 1159-1167.

14. Riyani K., Setyaningtyas T., and Dwiasi D.W. 2015. Synthesis and Characterization of TiO2-Cu Photocatalysts. Molecular Journal. 10(2), 104-111.

15. Salam A., Agustina T.E., and Mohadi R. 2018. Photocatalytic Degradation Of Procion Red Synthetic Dye Using ZnO-Zeolite Composites. International Journal of Scientific \& Technology Research. 7(8), 54-59.

16. Saravanan R., Gupta V.K., Narayanan V., and Stephen A. 2013. Comparative Study on Photocatalytic activity of $\mathrm{ZnO}$ Prepared By Different Methods. Journal of Molecular Liquids. 181, 133-141.

17. Sharfan N., Shobri A., Anindria F.A., Mauricio R., Tafsili M.A.B., and Slamet. 2018. Treatment Of Batik Industry Waste With A Combination Of Electrocoagulation And Photocatalysis. International Journal of Technology. 5, 936

18. Viswanathan B. 2018. Photocatalytic Degradation of Dyes: An Overview. Current Catalysis. 7(1), 1-25.

19. Wismayanti D., Diantariani N.P., and Santi S.R. 2015. Preparation of Activated ZnO-Charcoal Composite as Photocatalyst to Degrade Methylene Blue Dyestuff. Journal of Chemistry. 9(1), 109-116.

20. Wulandari D., Nasruddin E, and Djubaedah. 2019. Selectivity of Water Adsorbent Characteristic on Natural Zeolite in Cooling Application. Journal of Advanced Research in Fluid Mechanics and Thermal Sciences. 55(1), 111-11.

21. Zawadzki P., Kudlek E., and Dudziak M. 2018. Kinetics of the Photocatalytic Decomposition of Bisphenol A on Modified Photocatalysts. Journal of Ecological Engineering. 19(4), 260-268. 